\title{
THEME EDITORIAL
}

\section{Listening to diverse knowledge systems}

\section{NIKHIL GOVIND}

To some, the idea of health that is not beholden to strict notions of biomedical science is already misbegotten. This editorial cannot address this audience, for it believes that it is worth listening to varied knowledge systems. There is now an increased acceptance that the alienation felt by many towards contemporary health practice needs to be taken seriously. This issue contains six articles on the theme of diverse/traditional medical systems, and the need for a nuanced response to the questions they raise with regard to mainstream health practices. One accepts that these diverse/traditional medical systems may be misused, or insufficiently understood; the articles in this issue by Hurford, Rana, and Sachan (1), as well as by Ransing, Kar and Menon make this amply clear (2).

It is useful to distinguish at least three layers of analysis - a) the knowledge systems designated as AYUSH (Ayurveda, Yoga and Naturopathy, Unani, Siddha, Sowa-Rigpa and Homeopathy); b) the institutional context of government and private colleges, certifications, accreditations and so on; and c) the communication of the ideas/practices of these systems. The Hurford et al article is mainly directed at the third layer of communication (1). Other articles in this volume discuss the institutional issues be it AYUSH-inflected mental healthcare delivery (2), or the unregulated growth of homoeopathy colleges in the private sector - and government passivity with regard to policy, clinical care, and livelihood opportunities for the doctors involved (3). All these articles raise urgent points - poorly conceptualised policy-making has resulted in inadequate, confused, and uncertain care, and unhappiness for both doctor and patient.

Two other articles in the issue bring to the fore the knowledge system itself. Sebastian asks if there is any necessary relationship between Ayurveda and more typically orthodox Vedic knowledge systems. He argues that they may overlap and influence each other, but that neither system is reducible to the other (4). Similarly, GL Krishna, in the other article in the issue concerned with the knowledge system in itself, argues and hopes for a "new dawn" (5). The author believes that Ayurveda had a long and glorious tradition, but then there was a period of stagnation - and the only way to revive it today is to take the best from the admitted heterogeneity of scientific method. A fearless new synthesis may then be carved - for this, it is imperative that Ayurveda be shorn of dogma. One cannot, for example, in good conscience believe any more that semen is produced in the marrow. To disbelieve many facts is not to disbelieve the whole - this is akin to those who look at religious texts and believe that a single wrong fact discredits the whole. Thus, Krishna's article asks us to actively discard many beliefs in the harsh light of contemporary method (5).

It is invigorating that such a multi-faceted discussion is being held at all. This editorial concedes that there is much abuse, and many institutional obstacles — but the heart of what follows seeks to engage the conceptual/knowledge system level of alternative medicine. For without asking questions at that epistemological level, the institutional and communicative layers become moot.

Though governmental funding and support for alternative systems is welcome, there are dangers when this enthusiasm is not executed carefully. It is worth restating that the creation and development of knowledge works slowly - and can suffer equally from a lack of enthusiasm and support, as from an excess of it. The wrong type of support — impatient, dogmatic, shallow — can also kill the types of nurture that alternative systems need. One cannot solve a problem by withholding or throwing money at it. Rather, like these systems themselves, which grew over centuries and in different cultural and patronage contexts, policy must do the hard work not only of raising money, but also of designing the right administrative structures, the right balances of profit and equity, the right leadership, the optimised transmission and growth of hard-won insights and so on. Politicisation -

Author: Nikhil Govind (nikhilgovind@hotmail.com), Associate Professor and Head, Manipal Centre for Humanities, Manipal Academy of Higher Education, Manipal 576 104, Karnataka, INDIA

To cite: Govind N. Listening to diverse knowledge systems. Indian J Med Ethics. 2022 Jan-Mar; 7(1) NS: 5-7. DOI: 10.20529/IJME.2022.002

(c) Indian Journal of Medical Ethics 2022 
even in support - does more harm than good, for it also polarises and puts the theorists and clinicians under undue pressure, compromising the growth of these systems.

If there is to be a revival of these systems, hard questions have to be asked. The very nomenclature of AYUSH is obscure - it cannot simply be a hastily put together basket of all non-normative "others". What links Ayurveda, Yoga, Unani, Homoeopathy, and so on? Is it just the tokenism of inclusion given that these are systems so widely variant in their histories, repertoire, basic assumptions of the cosmos and the human body, and such like? The main government repository (https://www.ayush.gov.in) is meagre and confusing - naturopathy, for example, is now prominently added, with little explanation of how it fits, or indeed what it is. And the site is rather unnecessarily overwhelmed by Covid information, when most of these systems have in the past emphasised that they work best for long-term ailments rather than immediate infection (6). Its presence on social media forums such as Twitter, is hardly more illuminating, mostly showing politicians inaugurating hospitals, or doling out recipes.

Thus, instead of a catchall policy, what one needs is a deeper, multi-dimensional engagement. Precisely because there is an openness to alternative medical philosophies, one needs to take a step back and seek to properly understand the foundations of these traditions. In this issue, there is a discussion of the distinguished ethical lineage of Unani (7). Let us similarly look, in the briefest way, at the yoga-sutras (8). The precise extent to which yoga (like Ayurveda) belongs more to ritual orthodoxy or to the dissenting (shramanic) traditions matters less than the content of the sutras themselves. Here, certainly, the notion of health (like in most traditional systems) includes an insistence on a fullness of well-being, the development of a spiritual interiority and individuality, rather than the cure for a clear-cut pathology that is the norm in biomedical treatments. In this context, it may usefully be remembered that biomedicine is itself evolving, and the greater emphasis that is nowadays placed on mental health and overall well-being is itself a sign that the systems can talk to each other and not be seen as simple oppositions of traditional and modern, East and West, etc.

One must realise that varied knowledge systems need to evolve and learn from each other. Speaking in broad terms, modern Euro-American medicine has delinked disease from any ethical or emotional context. One is ill, and so takes a pill. But most traditional systems emphasise the entirety of a person's self - illness is connected to larger ideas of ethical, emotional and spiritual being. The yoga-sutras make little distinction between ill-health, wrong cognition, and inordinate human greed. Finally, health is inseparable from freedom: "inward consciousness is attained, and obstacles do not rise" (8: sutra 1.29; 118). This results in both good health as well as an ethical disposition: "Clarification of the mind [results] from the cultivation of friendliness towards the happy, compassion for those who suffer, sympathetic joy for the good, and equanimity toward those who lack goodness" (8: sutra 1.33;119). The clinical encounter is a moral encounter between patient and doctor, both of whom heal each other. Here again is Sushruta from the Ayurvedic tradition: "The model physician is ... clean, pure, brave and supplied with accessories and drugs; who has an unperturbed mind; who is wise, assiduous, adept and dedicated to truth and virtue" as cited in Valiathan (9: verse 24).

No doubt all this is much idealised. Nevertheless, the use of traditional systems must not simply be a matter of isolating some molecule in a formula, and then commercialising it or proclaiming the glory of Indian medicine. Unfortunately, this is much of what is encouraged and done in the name of AYUSH research (10). While it is far beyond the scope of this editorial to comment on protocols such as the clinical trial requirements of AYUSH drugs, the point can certainly be made that beyond the token invocation of Caraka, Sushruta etc, the protocol reads very much in the tradition of biomedicine, and is inadequately engaged with the epistemological or textual foundations that must mark our contemporary engagement with AYUSH traditions (6). The fond hope of a deeper engagement had been articulated helplessly over a decade ago: "research in Ayurveda [needs to be] unburdened by herbal product development and global marketing" (9: Preface). This call has clearly not been heeded, or even understood. To respond to traditional systems, one has to take stock of the fullness of their world-view. To be sure, some aspects of those world views may need to be jettisoned. Likewise, a love for traditional medicine cannot emerge from merely the alienation one feels while navigating the current healthcare system. One can claim any regard for these systems only if one has taken some care - preferably over decades — to delve into its practices as either doctor or patient/practitioner; at all times, an attempt to engage with the actual textual traditions (even to disagree) is imperative. The humanities provide extensive models of fruitful textual engagement - histories, sociologies, cultural studies of medicine - and these need to be made integral to the syllabi and research agendas of health pedagogy (11).

The other side of the equation is the patient/consumer. Here too, the great successes in the increased importance given to narratives such as those of sexuality, mental health and so on need to be replicated. Barring a few articles, there have been unfortunately too few autobiographies or memoirs of our current health encounters with traditional healing practices (12). Most AYUSH doctors talk in purely biomedical terms of illness/cure, with the occasional "miraculous" recovery thrown in. Rather, what is the need of the decade is a more sustained long-term engagement with health that is an aspect of one's deepest personal and emotional flourishing. Similarly, little attention has been paid in syllabi to involving patient experiences - this is of course equally true for mainstream medical discourse, which also routinely neglects patient or citizen narrative (13). 
One ends, thus, with the hope for conversation and growth on both sides - neither traditional nor normative medicines can do without each other — and an optimist would hope for a mutually compounding, respectful and thoughtful growth on both sides.

\section{References}

1. Hurford B, Rana A, Sachan RSK. Narrative-based misinformation in India about protection against Covid-19: Not just another "moo-point". Indian J Med Ethics. 2022 Jan-Mar;7(1) NS: 22-26. Published online first on July 5, 2021. https://doi.org/10.20529/IJME.2021.050

2. Ransing R, Kar SK, Menon V. Alternative medicine for mental healthcare under the Mental Health Care Act, 2017: Future implications and concerns. Indian J Med Ethics. 2022 Jan-Mar;7(1)NS: 37-41. https://doi.org/10.20529/IJME.2022.004

3. Bansode M. Homoeopathic medical education in Maharashtra: growth and challenges. Indian J Med Ethics. 2022 Jan-Mar;7(1) NS: 27-32. Published online first on August 28, 2021. https://doi.org/10.20529/IJME.2021.065

4. Sebastian CD. Ayurveda and the medical knowledge in ancient India: Shadows and realities. Indian J Med Ethics. 2022 Jan-Mar;7(1) NS: 8-15. Published online on November 12,2021. https://doi.org/10.20529/IJME.2021.085

5. Krishna GL. Ayurveda awaits a new dawn. Indian J Med Ethics. 2022 Jan-Mar;7(1) NS: 16-21. Published online first on December 2, 2021. https:// doi.org/10.20529/IJME.2021.093

6. Wujastyk D. Well-Mannered Medicine:Medical Ethics and Etiquette in Classical Ayurveda. Oxford:Oxford University Press, 2012.

7. Javed G, Kumar N. Bioethics in Unani medicine: Relevant quotes from Kamilussanah, a 10th century Unani manuscript. Indian J Med Ethics. 2022 JanMar; 7(1) NS: 33-36. https://doi.org/10.20529/IJME.2022.003

8. Chapple C. Yoga and the Luminous: Patanjali's Spiritual Path to Freedom, New York: State University of New York Press, 2008.

9. Valiathan MS. The Legacy of Susruta. Hyderabad: Orient Longman, 2007.

10. Central Council for Research in Ayurvedic Sciences. General Guidelines for Clinical Evaluation of Ayurvedic Interventions. New Delhi: CCRAS; 2018.

11. Prabhu G. The disappearing act: Humanities in the medical curriculum in India. Indian J Med Ethics. 2019 Jul-Sep;4(3) NS:194-8. https://doi.org/ 10.20529/IJME.2019.044

12. Prabhu G. My body is a lantern: Oscillopsia and an experience of Ayurveda. Indian J Med Ethics. 2019 Apr-Jun;4(2) NS:154-6. https://doi.org/10.20529/ IJME.2018.103

13. Govind N, Chowkhani K. Integrating concerns of gender, sexuality and marital status in the medical curriculum. Indian J Med Ethics. 2020 Apr-Jun; 5(2)NS:92-4. https://doi.org/10.20529/IJME.2020.039

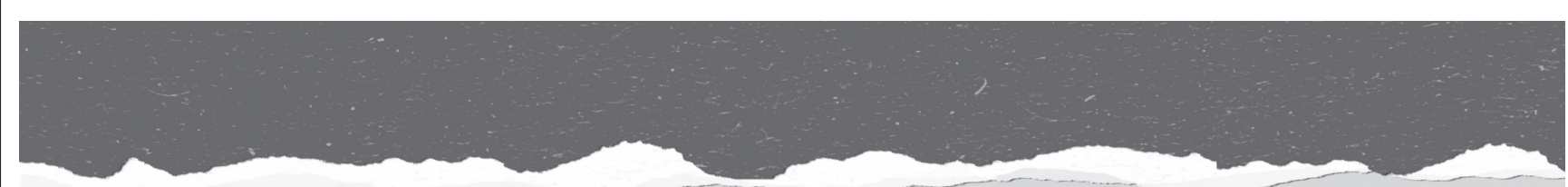

THE STEADY DRUMBEAT OF INSTITUTIONAL CASTEISM: Recognise Respond Redress

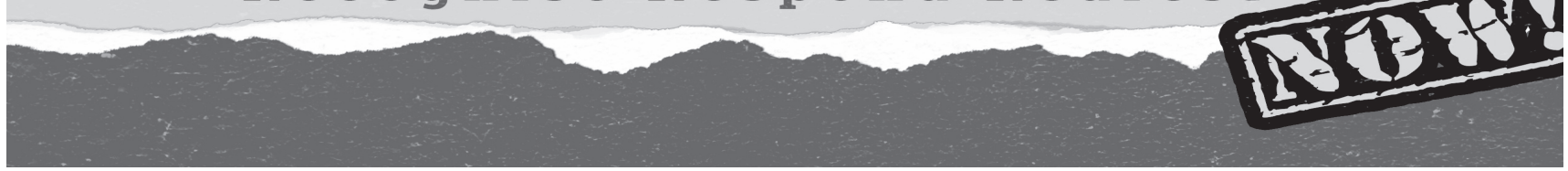

Forum Against Oppression of Women, Forum for Medical Ethics Society, Medico Friend Circle, Peoples' Union of Civil Liberties, Maharashtra

September 2021

The tragic waste of the death by suicide of Dr Payal Tadvi, resident doctor at the BYL Nair Hospital, Mumbai, on May 22, 2019, stirred the nation's conscience... for a while. That the first woman from the Adivasi Muslim Bhil Community, a scheduled tribe, to pursue a post-graduation in medicine was driven to death in such a manner amounted to "institutional murder".

Since the 1990s, the entry of a visible number of students from marginalised castes has brought overt tensions into university campuses, with constant challenges to the affirmative constitutional policies of reservations in education and employment for the SC and ST communities. Alongside this, growing privatisation in higher education, and attempts to integrate India into the global knowledge economy, have had an impact. This enquiry attempts to study the combined effect of all these trends, specifically in the case of medical education.

The full report can be accessed at: https://fmesinstitute.org/wp-content/uploads/2021/09/The-Steady-Drumbeat-ofInstitutional-Casteism-Recognize-Respond-Redress_Final-report_27Sept21.pdf 